\title{
Holographic Grating Erasing Characteristics by Non-polarized Beam in Amorphous Chalcogenide Thin Films
}

\author{
Ki-Nam Lee, Jeong-Il Park, and Hong-Bay Chung ${ }^{\mathrm{a}}$ \\ Department of Electronic Materials Engineering, 3DRC ${ }^{a}$, Kwangwoon University, \\ Wolgye 1-dong, Nowon-gu, Seoul 139-701, Korea \\ ${ }^{a}$ E-mail : hbchung@kw.ac.kr
}

(Received December 23 2005, Accepted June 7 2006)

\begin{abstract}
In the present work, we investigated the holographic grating erasing method by means of the optical method. It was formed the grating under the interference of holographic recording He$\mathrm{Ne}$ laser beams on chalcogenide $\mathrm{As}_{40} \mathrm{Ge}_{10} \mathrm{Se}_{15} \mathrm{~S}_{35}$ thin film with various film thickness and erased the holographic grating by non-polarized He-Ne laser beam. As the results, the recording grating erased the $80 \%$ of formed grating by non-polarized $\mathrm{He}-\mathrm{Ne}$ laser beam. It was confirmed that the erasing characteristics by non-polarized laser beam need to improve the focusing of beam and the control of beam intensity. And then it can be expected as the application possibility of rewritable holographic memory technology.
\end{abstract}

Keywords : Amorphous, Chalcogenide, Non-polarized beam, Holographic grating, VAPs

\section{INTRODUCTION}

In the recent years, a holographic memory has received the attention as a technology that can provide an optical data storage high density and high speed, and it has held a promise in the direction of high-density optical data storage[1-3]. Holographic diffraction gratings are currently widely used in various areas of science and engineering. Those based on both of the surface relief structure and refractive index modulation have the application possibility for the display, data storage, optical elements and devices. With the discovery of the photo-refractive materials are considerable of interest for the development of all optical, such as high density optical data storage and, image processing.

Many different optical materials have been investigated in holographic data storage devices. Especially, amorphous chalcogenide thin films have become increasingly interested and attracted much attention as a new advanced and replaceable material because of their optical scalar and vectoral characteristics. Among these materials, amorphous AsGe-Se-S system chalcogenide thin films are known to be a suitable material for optical recording and data storage device. Because they have some unique advantages for the application of data storage, such as anisotropic characteristics, ie, large birefringence and dichroism, high spatial resolution, etc. Its high resolution makes it suitable for high-density data recording and building a nano-structure[4].

As we have been studied the improvement of hologram grating diffraction efficiency on chalcogenide thin film, it was found to need that the information recorded by a holographic method was entirely reduced or erased for the rewritable optical information storage device[5-8]. However, it has many difficult problems because the diffraction lattice can't be erased completely. In the present work, we predict the optical erasing method by means of non-polarized $\mathrm{He}-\mathrm{Ne}$ laser beam on amorphous chalcogenide As-Ge-Se-S systems which exhibit a good photo-refractive effect useful in hologram grating recording. In particular, the $\mathrm{As}_{40} \mathrm{Ge}_{10} \mathrm{Se}_{15} \mathrm{~S}_{35}$ composition, selected in the present work, shows the maximum change for reversible photostructural transformation in $\mathrm{As}_{40} \mathrm{Ge}_{10} \mathrm{Se}_{50-\mathrm{x}} \mathrm{S}_{\mathrm{x}}(\mathrm{x}=0,25,35$ at.\%) thin films[7-11].

To confirm the predicted optical way, we investigate on the focus of the improvement the grating efficiency and the erasing ratio how to get rid of the record data by the means of exposing non-polarized beam.

\section{EXPERIMENT}

Amorphous chalcogenide As-Ge-Se-S systems exhibit a good photo-refractive effect useful in scalar hologram grating recording. In particular, the $\mathrm{As}_{40} \mathrm{Ge}_{10} \mathrm{Se}_{15} \mathrm{~S}_{35}$ 


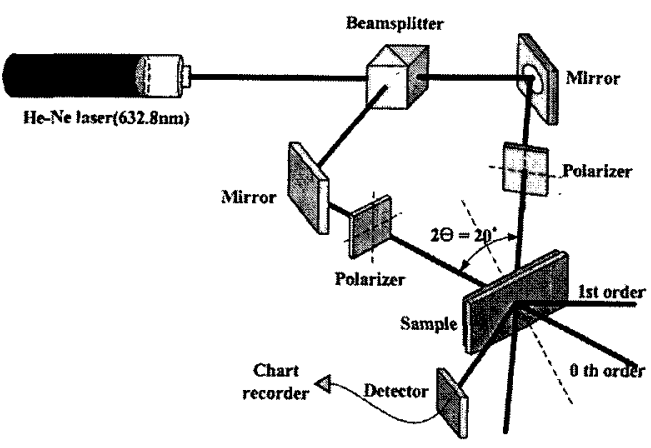

Fig. 1 Schematic diagram of the experimental setup to record the holographic gratings and observe the diffraction efficiency.

composition, selected in this work, shows the maximum change for reversible photo-structural transformation in $\mathrm{As}_{40} \mathrm{Ge}_{10} \mathrm{Se}_{50-\mathrm{x}} \mathrm{S}_{\mathrm{x}}(\mathrm{x}=0,25,35$ at.\%) thin films. An $\mathrm{As}_{40} \mathrm{Ge}_{10} \mathrm{Se}_{15} \mathrm{~S}_{35}$ bulk glass was fabricated by a conventional melt quenching technique[7-9]. An Ag film was deposited by thermal evaporation on Corning-glass7059 (density: $2.76 \mathrm{~g} / \mathrm{cm}^{3}, 50 \times 50 \times 1.2 \mathrm{~mm}$, refractive index: 1.50 at $780 \mathrm{~nm}$ ) in vacuum at $\sim 2 \times 10^{-6}$ Torr. The $\mathrm{a}-\mathrm{As}_{40} \mathrm{Ge}_{10} \mathrm{Se}_{15} \mathrm{~S}_{35}$ thin films were also prepared by thermal evaporation of the bulk at a deposition rate 0.2 $\mathrm{nm} / \mathrm{s}$ on glass substrates. The film thickness was monitored to be approximately $40 \sim 633 \mathrm{~nm}$ for chalcogenide thin films $(\lambda, \lambda / 2, \lambda / 4$, and $\lambda / 8)$.

Figure 1 shows the schematic diagram of the experimental setup for grating formation and observing the intensity of diffraction beam. A non-polarized $\mathrm{He}-\mathrm{Ne}$ laser beam (hv $=1.96 \mathrm{eV}$ ) was used as both a recording beam and a proving beam. A He-Ne laser beam is split into a reference beam and a recording beam using a beam splitter. As seen from Fig. 1, it represent BS= beam splitter, $\mathrm{M}=$ mirror, $\mathrm{S}=$ shutter for proving, $\mathrm{D}=$ detector (the optical power-meter, Newport 1815-C) and $\mathrm{CR}=$ chart recorder. The 0th and 1st present the orders of diffraction beams, respectively. The two beams after the reflection from the mirror are allowed to interfere at the sample device to form the holographic grating. The incident angle $(\Theta)$ for recording holographic gratings and the average intensity of probing (read-out) beam $\left(I_{0}\right)$ for evaluating the diffraction efficiency $(\eta)$ were $20^{\circ}$ and about $2.5 \mathrm{~mW} / \mathrm{cm}^{2}$, respectively. $\eta$ is determined as a quantity of $I_{d} / I_{0}$, where $I_{d}$ is the intensity of the 1st-order diffraction beam from the grating in transmission mode, which was monitored as a function of time using an optical power-meter. After it was formed the holographic grating on the chalcogenide thin film as Fig. 1, we investigated the holographic grating diffraction efficiency and then, try to erase the formed gratings by means of the optical method. At first, it was shielded off the recording beam to erase the formed grating and then, it exposed non-polarized light which the initial intensity ( $\mathrm{I}_{0}$ ) was $7.8 \mathrm{~mW} / \mathrm{cm}^{2}$.

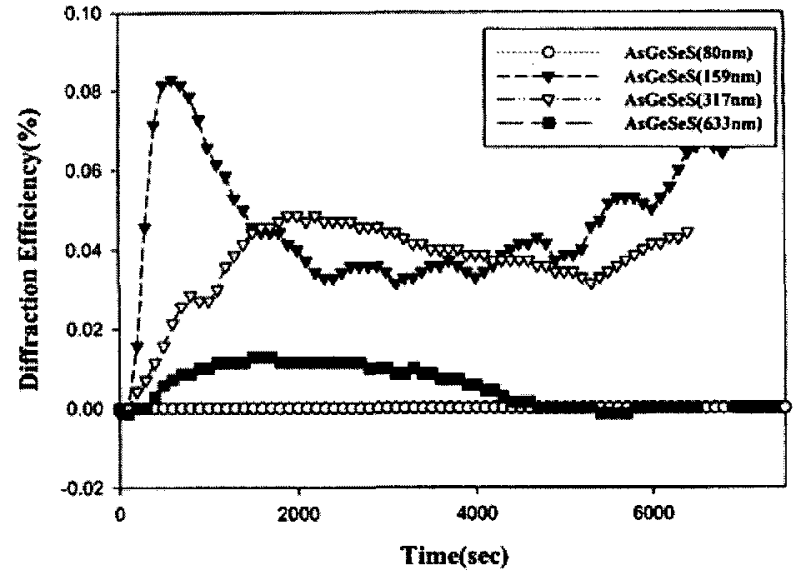

Fig. 2 Diffraction efficiency of holographic gratings in $\mathrm{As}_{40} \mathrm{Ge}_{10} \mathrm{Se}_{15} \mathrm{~S}_{35}$ thin film(80 633 nm) as a function of exposure time.

\section{RESULTS AND DISCUSSION}

Hologram recording by $\lambda=632.8 \mathrm{~nm}$ light in this film utilizes the photostructural changes of the native VAPs rather than the generation of the photo-induced VAPs. The native VAPs usually depend on the film fabrication process and exist even in non-illuminated chalcogenides, and their local environments. We believe that the photoinduced change in Urbach tail region by sub-band gap illumination $\left(\mathrm{hv}<\mathrm{E}_{\mathrm{OP}}\right)$ is different from that by phtodarkening effect by above-band gap illumination ( $h v>E_{O P}$ ). Of course, the electronic transitions of the extended band-to-localized state and between localized states have an influence on the photostructural change by illumination of $\mathrm{hv}<\mathrm{E}_{\mathrm{OP}}$. Until now, we have discussed a series of experimental results concerning the photoinduced anisotropy phenomena in amorphous chalcogenides on the basis of the native VAPs.

Figure 2 describes the diffraction efficiency of holographic gratings in $\mathrm{As}_{40} \mathrm{Ge}_{10} \mathrm{Se}_{15} \mathrm{~S}_{35}$ chalcogenide thin film with a various thickness as a function of exposure time. As seen from Fig. 2, it represents the lowest diffraction efficiency, $10^{-4} \%$ at $\lambda / 8(80 \mathrm{~nm})$ and the highest diffraction efficiency $0.08 \%$ at $\lambda / 4(159 \mathrm{~nm})$ of $\mathrm{As}_{40} \mathrm{Ge}_{10} \mathrm{Se}_{15} \mathrm{~S}_{35}$ chalcogenide thin film and then, it seems that the diffraction efficiency has the tendency of decrease with the increase of film thickness. It was considered that the intensity of 1st order of transmission beam decrease inside thin film thickness because the transmission type holographic grating by the interference effect of two beam are formed within one period of recording beam $(\lambda=633 \mathrm{~nm})$ at the thin film thickness under $633 \mathrm{~nm}$. 


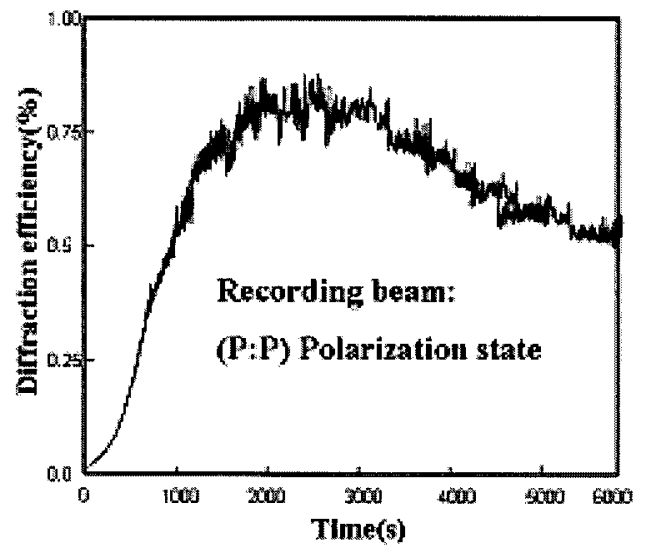

(a)

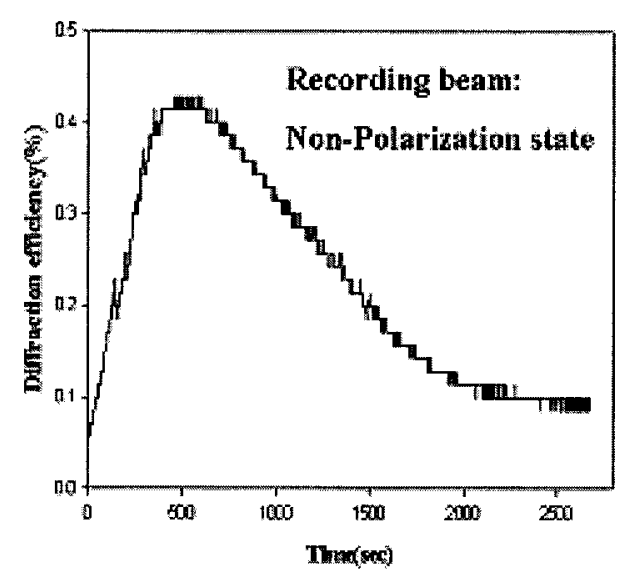

(b)

Fig. 3 Diffraction efficiency by the polarization state of recording beam in $\mathrm{As}_{40} \mathrm{Ge}_{10} \mathrm{Se}_{15} \mathrm{~S}_{35}$ thin film as a function of exposure time (a) (P:P) polarization state (b) non-polarization state.

Figure 3 describes the results of obtained diffraction efficiency at $(\mathrm{P}: \mathrm{P})$ polarization and non-polarization state of $\mathrm{He}-\mathrm{Ne}$ laser. As the results of (P:P) polarization state in Fig. 3(a), it increase abruptly at $300 \mathrm{sec}$ and then, it saturate the maximum value at $2,000 \mathrm{sec}$. Maximum diffraction efficiency was about $8 \%$, and it was shown the characteristic of maintaining the constant saturation value and remaining the formed grating. For a phase polarization holography, the polarization state of two beams occur the interference with the phase difference and it equals the intensity of interference pattern inside thin film. It was confirmed that it was maintained the constant value, because the formed gratings with these method acts differently on the path difference on space and the polarization state of the reference beam. Figure 3 (b) describes the change of diffraction efficiency with the exposure time at non-polarized state. It describes the maximum saturated value, $0.4 \%$ at about $500 \mathrm{sec}$.

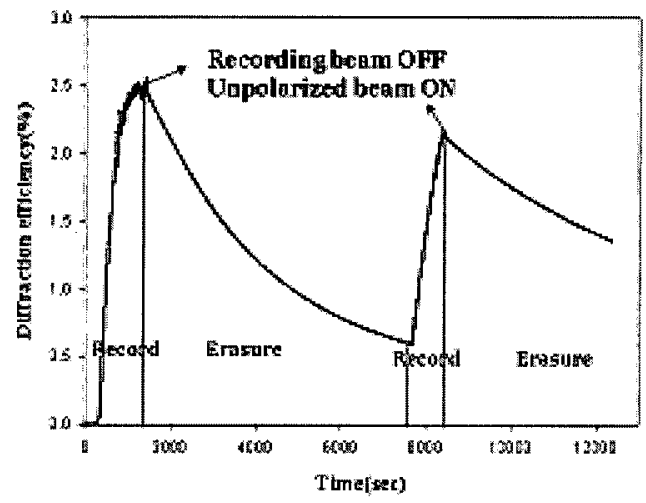

Fig. 4 Polarization holographic recording (P:P) and erasing by non-polarized beam on chalcogenide $\mathrm{As}_{40} \mathrm{Ge}_{10} \mathrm{Se}_{15} \mathrm{~S}_{35}$ thin film.

Then after the maximum value, it shows the decreasing tendency with the time, and it represents $0.01 \%$ at 2,000 sec. As the time passes, it was reached the saturation by a long time inducing effect of a weak beam at all parts of thin film, especially, between the grating width and then, it was created a number of new gratings. It was confirmed that the decreasing tendency of grating efficiency after the saturation means the progress of new forming a grating with the constant directionality by the superposition effect of two recording beams.

Figure 4 describes the graph of recording and erasing of holographic gratings with (P:P) polarized and nonpolarized beam on chalcogenide $\mathrm{As}_{40} \mathrm{Ge}_{10} \mathrm{Se}_{15} \mathrm{~S}_{35}$ thin film. After it was recording for $1,300 \mathrm{sec}$ and formed the grating of saturation diffraction efficiency, $2.5 \%$, it was shuttered out the recording beam and exposed the nonpolarized beam to erase the formed grating. As the results, it was found the erasing of grating, $80 \%$ with the initial abrupt decrease of grating efficiency. It was confirmed that the decrease of grating efficiency was shown due to remove the local modulation of refraction index. $\Delta \mathrm{n}$ with the randomness of the directionality by non-polarized beam direction used the erasing beam. And exposing two recording beam on chalcogenide thin film, repeatedly, it was shown the lower diffraction efficiency than initial formed grating. It was confirmed that chalcogenide thin film which has the grating destroyed by non-polarized beam has formed with redirectionality by the polarized beam and has the lower directionality than initial formed grating direction.

\section{CONCULUSION}

We have investigated the holographic grating erasing method by means of the optical method. It was formed the diffraction grating under the interference of (P:P) 
polarized holographic recording $\mathrm{He}-\mathrm{Ne}$ beams on chalcogenide $\mathrm{As}_{40} \mathrm{Ge}_{10} \mathrm{Se}_{15} \mathrm{~S}_{35}$ thin film with various film thickness and erased the holographic grating by nonpolarized $\mathrm{He}-\mathrm{Ne}$ laser beam. As the results, the recorded holographic grating can be erased the $80 \%$ of formed grating by exposing the non-polarized He-Ne laser beam. It was confirmed that the erasing characteristics by nonpolarized laser beam need to improve the focusing of beam and the control of beam intensity. And then it can be expected as the application possibility of rewritable holographic memory technology.

\section{ACKNOWLEDGMENTS}

This research was supported by the MIC(Ministry of Information and Communication), Korea, under the ITRC(Information Technology Research Center) support program supervised by the IITA(Institute of Information Technology Assessment)(IITA-2005-C1090-0502-0038).

\section{REFERENCES}

[1] J. Ashley and G. T. Sincerbox, "Holographic data storage", IBM J. Res. Develp., Vol. 44, No. 3, p. $341,2000$.

[2] H. Y. Lee, S. H. Park, J. Y. Chun, and H. B. Chung, "Photoinduced transformations in amorphous $\mathrm{Se}_{75} \mathrm{Ge}_{25}$ thin film by $\mathrm{XeCl}$ excimer-laser exposure", J. Appl. Phys., Vol. 83, p. 5381, 1998.

[3] H. Fritzsche, "Toward understanding the photoinduced change in chalcogenide glasses", Semiconductors, Vol. 32, No. 8, p. 850, 1998.
[4] S. J. Jang, C. H. Yeo, J. I. Park, H. Y. Lee, and H. B. Chung, "The photoinduced anisotropy(PA) by $\mathrm{Ag}$ polarized-photodoping in amorphous chalcogenide thin films", J. of KIEEME(in Korean), Vol. 13, No. 6 , p. 533, 2000.

[5] H. Y. Lee, M. S. Kim, and H. B. Chung, "The analysis of $\mathrm{Ag}$ doping mechanism by photoexposure", J. of KIEEME(in Korean), Vol. 8, No. 4, p. $472,1995$.

[6] L. Nikolova and T. Tbdorov, "Diffraction efficiency and selectivity of polarization holographic recording", Opt. Acta., Vol. 31, p. 579, 1984.

[7] H. B. Chung, H. Y. Lee, S. H. Park, and J. Y. Chun, "Structural and optical properties of obliquely deposited amorphous $\mathrm{As}_{40} \mathrm{Ge}_{10} \mathrm{Se}_{15} \mathrm{~S}_{35}$ thin film as anisotropic materials", The proceeding of ICEE'98, Vol. 2, p. 927, 1998.

[8] C. H, Yeo, S. J. Jang, J. I. Park, H. B. Lee, and H. B Chung, "The measurement on diffraction efficiency in polarization holography using amorphous chalcogenide thin films", J. of KIEEME(in Korean), Vol. 12, No. 12, p. 1192, 1999.

[9] K. N. Lee, C. H. Yeo, S. J. Yang, and H. B. Chung, "The Elimination characteristics by impressed voltage of holography grating in chalcogenide thin film", Trans. EEM, Vol. 5, No. 6, p. 219, 2004.

[10] J. I. Park, J. T. Lee, C. H. Yeo, Y. J. Lee, J. B. Kim, and H. B. Chung, "Polarization dependence of holography grating in chalcogenide film", Jpn. J. Appl. Phys., Vol. 42, p. 5090, 2003.

[11] J. H. Park, J. I. Park, E. S. Kim, and H. B. Chung, "Amorphous-Si transmittance gratings prepared by $\mathrm{Ga}^{+}$-focused-ion-beam milling and their polarization characteristics", Jpn. J. Appl. Phys., Vol. 41, p. 4271, 2002. 